\title{
Cervical Laminectomy for the Treatment of Chronic Caudal Cervical Spondylomyelopathy in a Dog
}

\author{
Guilherme Sembenelli, Monica Carolina Nery Wittmaack, Levi Oliveira, Paola Castro Moraes, \\ Bruno Watanabe Minto \& Luis Gustavo Gosuen Gonçalves Dias
}

\begin{abstract}
Background: Cervical spondylomyelopathy (CSM) is a common disease of the cervical spine, and causes neurogenic disorders commonly diagnosed in large and giant breeds dogs. There are many surgical procedures proposed for the treatment of CSM. Although many authors report a high success rate (between 70\% and 90\%) after surgical procedures, the high number of techniques described reflects the difficulty in treating this disorder. The objective of this paper is to report a case of CSM with chronic ventral compression (intervertebral disc extrusion) that was treated with dorsal decompression, and to demonstrate the effectiveness of the decompressive technique through pre- and post-operative myelograms. Case: A 9-year-old Doberman Pinscher dog weighing $41.8 \mathrm{~kg}$ presented due to a history of tetraparesis. Neurological examination did not reveal any alteration in mental status. There was absence of conscious proprioception on the four limbs; the pelvic limbs were more severely affected. Bilateral patellar hyperreflexia and normal flexor withdrawal reflex were observed on the hind limbs. There was decreased flexor withdrawal reflex and increased extensor tone on the forelimbs. The patient exhibited pain during caudal cervical palpation, and no alterations were seen on the cutaneous trunci reflex. Superficial pain was absent in the hind limbs; forelimbs exhibited presence of motor function with severe paresis. Survey radiographs revealed intervertebral disc space narrowing between C6-C7. A myelogram revealed ventral and dorsal compressions of the spinal cord in the C6-C7 area. Surgical treatment was elected, and laminectomy of the sixth and seventh cervical vertebrae was performed. Improvements were progressive on evaluations made on the seventh, eighteenth, forty-fifth, and sixtieth days after surgery. On the forty-fifth day after surgery, the patient was able to walk with the aid of a support sling, but was incapable of standing and walking without help. Muscle atrophy and paresis progressively improved up to the sixtieth day after surgery, but such improvement was not enough for the patient to get up and walk without the aid of the sling. In view of the evolution of the clinical signs during the post-operative period, another myelogram was performed to check if the extruded intervertebral disc, which was not removed during laminectomy, was still causing spinal cord compression. In comparison to the first myelogram, the compression was significantly attenuated by the surgical procedure. In this examination, the contrast medium columns were minimally compromised by the presence of herniated material; because of that, we opted not to perform a second surgical intervention for removal of herniated disc content.

Discussion: Cervical laminectomy is indicated primarily for cases of dorsal compression associated with osteoarthritic changes of facet joints, malformation of the dorsal lamina, or ligamentum flavum hypertrophy however, this technique has also been used to treat ventral compressions, especially if they are multiple. There are no reports of direct comparison between laminectomy and other surgical techniques for the treatment of chronic ventral compressions; consequently, the choice of the technique depends on the surgeon's experience and preference. Some authors argue that cervical laminectomy is not enough to attenuate the compression caused by the disc because this technique does not allow removal of the herniated disc material located ventrally. However, in the case reported here, a comparison between pre- and postoperative myelograms revealed that even though the herniated material was not removed, dorsal decompression allowed dorsal dislocation of the spinal cord and, consequently, promoted considerable attenuation of ventral compression.
\end{abstract}

Keywords: Wobbler syndrome, nervous system, spinal cord, cervical vertebrae. 
G. Sembenelli, M.C.N.Wittmaack, L. Oliveira, P.C. Moraes, B.W. Minto \& L.G.G.G. Dias. 2016. Cervical Laminectomy for the Treatment of Chronic Caudal Cervical Spondylomyelopathy in a Dog.

\section{INTRODUCTION}

Cervical spondylomyelopathy (CSM) is a common disease of the cervical spine, and causes neurogenic disorders commonly diagnosed in large and giant breeds dogs [8]. Clinical signs of CSM are usually chronic and progressive [8]. Evaluation of ambulation is indispensable, as proprioceptive ataxia is seen in the majority of dogs with CSM [4]. Definitive diagnosis of CSM is established by means of imaging exams as myelogram, computed tomography or magnetic resonance $[15,18]$.

There are many surgical procedures proposed for the treatment of CSM. Although many authors report a high success rate (between $70 \%$ and $90 \%$ ) after surgical procedures, the high number of techniques described reflects the difficulty in treating this disorder [5].

There are two basic types of surgery: those in which direct decompressive techniques are used, and those in which indirect decompressive techniques are employed [4]. The predominant factor for the choice of the surgical procedure is the analysis of the spinal cord by imaging methods [8]. The ventral slot technique is mainly indicated for cases in which one single static ventral compression is present [9], while cervical laminectomy is indicated for cases of dorsal compressions, even though it can also be used to decompress multiple ventral spinal cord compression lesions [6].

The objective of this paper is to report a case of CSM with chronic ventral compression that was treated with dorsal decompression, and to demonstrate the effectiveness of the decompressive technique through pre- and post-operative myelograms.

\section{CASE}

A 9-year-old Doberman Pinscher dog weighing $41.8 \mathrm{~kg}$ presented due to a history of tetraparesis. The patient had been treated by a colleague with anti-inflammatory drugs, physical therapy and acupuncture. During the whole time it had been treated conservatively, the patient exhibited ambulatory tetraparesis and proprioceptive ataxia; however, there was worsening of neurological signs and evolution to non-ambulatory tetraparesis 12 months later.

On the first appointment, the patient remained in lateral recumbency and was unable to move the neck. Neurological examination did not reveal any alteration in mental status. There was absence of conscious proprioception on the four limbs; the pelvic limbs were more severely affected. Bilateral patellar hyperreflexia and normal flexor withdrawal reflex were observed on the hind limbs. There was decreased flexor withdrawal reflex and increased extensor tone on the forelimbs. The patient exhibited pain during caudal cervical palpation, and no alterations were seen on the cutaneous trunci reflex. Superficial pain was absent in the hind limbs; forelimbs exhibited presence of motor function with severe paresis. Survey radiographs revealed intervertebral disc space narrowing between C6-C7 (Figure 1A).

A myelogram revealed ventral and dorsal compressions of the spinal cord in the C6-C7 (Figure 1B). Surgical treatment was elected, and laminectomy of the sixth and seventh cervical vertebrae was performed. The prescription for postoperative care included $30 \mathrm{mg} / \mathrm{kg}$ cephalexin (Cefalexina Teuto $\left.^{\circledR}\right)^{1}$ twice a day for 10 days, $1 \mathrm{mg} / \mathrm{kg}$ omeprazole $\left(\text { Omeprazol Medley }{ }^{\circledR}\right)^{2}$ once a day for 15 days, $5 \mathrm{mg}$ / $\mathrm{kg}$ firocoxib $\left(\text { Previcox }^{\circledR}\right)^{3}$ once a day for 10 days, 4 $\mathrm{mg} / \mathrm{kg}$ tramadol chlorhydrate (Cloridrato de Tramadol Neo Química $\left.{ }^{\circledR}\right)^{4}$ three times a day for 10 days, and $25 \mathrm{mg} / \mathrm{kg}$ dipyrone $\left(\text { Novalgina }^{\circledR}\right)^{5}$ three times a day for 7 days.

Improvements were progressive on evaluations made on the seventh, eighteenth, forty-fifth, and sixtieth days after surgery. Improvement on neck movement and decrease on spasticity of forelimbs were observed on the seventh day after surgery; however, superficial pain was still absent and deep pain was present on the hind limbs. On this same day, the patient was still incapable of remaining on sternal recumbency, and physical therapy was recommended.

On the eighteenth day after surgery, there was recovery of hind limb motor function, albeit with severe paresis. The patient was then capable of remaining in the esternal position. On the forty-fifth day after surgery, the patient was able to walk with the aid of a support sling, but was incapable of standing and walking without help. Muscle atrophy and paresis progressively improved up to the sixtieth day after surgery, but such improvement was not enough for the patient to get up and walk without the aid of the sling.

In view of the evolution of the clinical signs during the post-operative period, another myelogram was performed to check if the herniated intervertebral disc, which was not removed during laminectomy, 
was still causing spinal cord compression. In comparison to the first myelogram, the compression was significantly attenuated by the surgical procedure. In this examination, the contrast medium columns were minimally compromised by the presence of herniated material (Figure 1C, D, E, F and G); because of that, we opted not to perform a second surgical intervention for removal of herniated disc content.

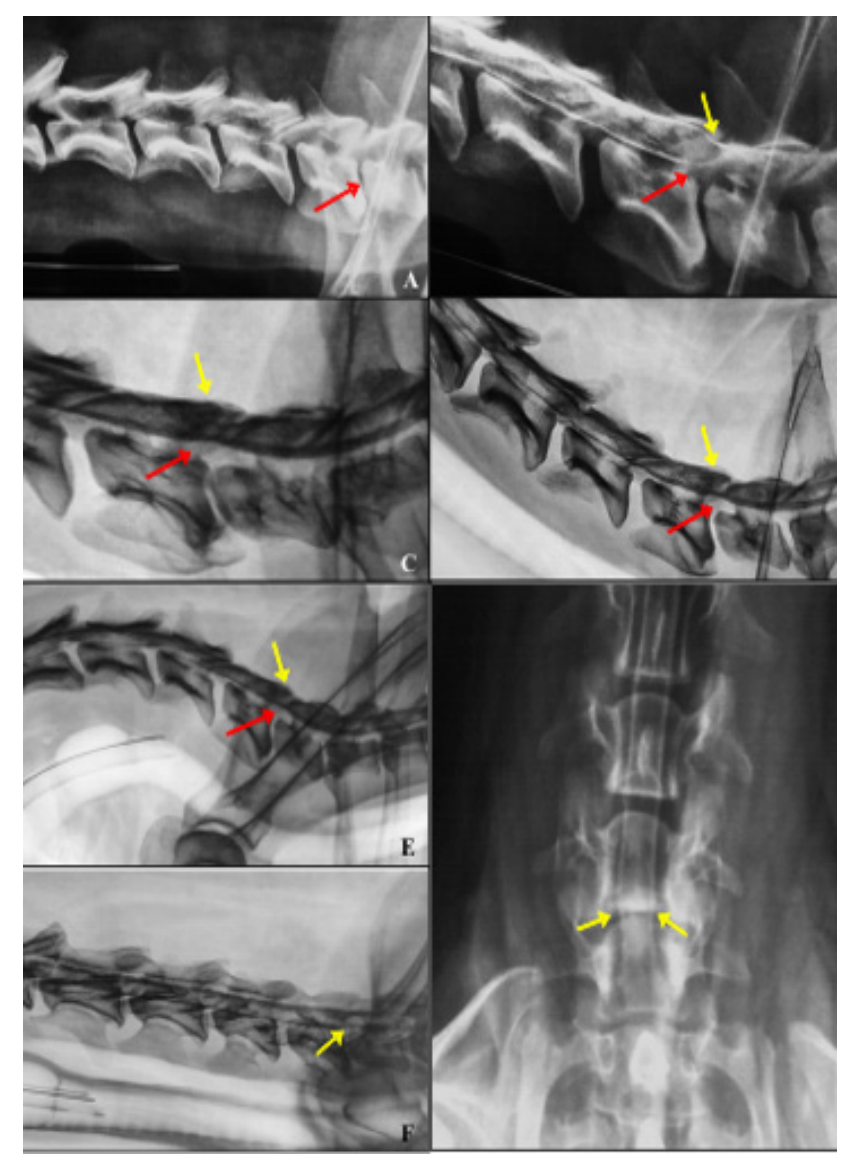

Figure 1. Survey and contrast (myelogram) radiographs of the cervical spine of a 9-year-old, male, $41.8 \mathrm{~kg}$, non-ambulatory tetraparetic, Doberman pinscher dog. A- Lateral projection showing reduced intervertebral space between C6-C7 (arrow). B- Lateral projection myelogram showing compression of the ventral (black arrow) and dorsal (white arrow) surfaces of the spinal cord. CLateral projection mylogram forty-five days after laminectomy procedure showing absence of compression of the dorsal surface of the spinal cord (white arrow) and mild compression of the ventral surface of the spinal cord (black arrow). D- Extended position on lateral projection myelogram. Note absence of compression of the dorsal surface of the spinal cord (white arrow) and exacerbation of compression of the ventral surface owing to positioning (black arrow). E- Ventroflexed position on lateral projection myelogram demonstrating absence of compression of the dorsal surface of the spinal cord (white arrow) and mild compression of the ventral surface of the spinal cord (black arrow). F- Right oblique projection mylogram showing absence of spinal cord involvement (white arrow). G- Ventrodorsal projection mylogram showing absence of involvement of the lateral contrast columns (white arrows).

\section{DISCUSSION}

There is no consensus on what is the best surgical technique for the treatment of CSM, and many techniques have been reported $[17,20]$.

The cervical ventral slot procedure is used to access the vertebral canal and allow its visualization for decompression in patients with cervical disc disease, and it can be combined with the fenestration procedure [8]. The cervical ventral slot procedure is indicated mainly for cases of one single static ventral compression [9]; conversely, there are reports of complications associated with the use of this procedure in cases of chronic intervertebral disc disease. Calcification and adherence of the disc to the dura mater makes its removal difficult, and transoperative complications have been reported during an attempt to remove herniated material [1]. Herniated disc material triggers an extradural inflammatory reaction, which results in fibrous adherence between the dura mater and the disc material [10,19].

Although the ventral slot technique is indicated for single ventral compressions [9], a dorsal decompression technique was chosen in this case because a) it could avoid complications frequent in chronic cases of spinal cord compression caused by the intervertebral disc; b) dorsal compression (from the bone) was also present in this case; c) there was a possibility of rupture of the venous sinus.

Cervical laminectomy is indicated primarily for cases of dorsal compression associated with osteoarthritic changes of facet joints, malformation of the dorsal lamina, or ligamentum flavum hypertrophy $[7,11]$; however, this technique has also been used to treat ventral compressions, especially if they are multiple [12].

There are no reports of direct comparison between laminectomy and other surgical techniques for the treatment of chronic ventral compressions; consequently, the choice of the technique depends on the surgeon's experience and preference [14].

Some authors argue that cervical laminectomy is not enough to attenuate the compression caused by the disc because this technique does not allow removal of the herniated disc material located ventrally. However, in the case reported here, a comparison between pre- and postoperative myelograms revealed that even though the herniated material was not removed, dorsal decompression allowed dorsal dislocation of the spinal 
G. Sembenelli, M.C.N.Wittmaack, L. Oliveira, P.C. Moraes, B.W. Minto \& L.G.G.G. Dias. 2016. Cervical Laminectomy for the Treatment of Chronic Caudal Cervical Spondylomyelopathy in a Dog. Acta Scientiae Veterinariae. 44(Suppl 1): 156.

cord and, consequently, promoted considerable attenuation of ventral compression.

Analyses of magnetic resonance images have demonstrated that clinically normal Doberman pinschers can exhibit asymptomatic compression of the spinal cord. Therefore, spinal cord compression does not necessarily cause neurogenic signs [2,3]. Stenosis of the vertebral canal has been determined as the main mechanism for the development of neurogenic signs in CSM since all affected dogs have some degree of stenosis of the vertebral canal [2]. In view of the fact that ventral compression does not cause clinical signs in dogs without stenosis of the vertebral canal, dorsal laminectomy could play an important role on the main mechanism of CSM; since this technique increase the diameter of medulary canal.

In the case reported here, clinical signs improved progressively up to the sixtieth day after the surgery; however, complete improvement of the clinical signs was not observed on follow-up examinations between the ninetieth day and the fifth month after the surgery. The average recovery time described for this type of surgery is 3.6 months $[7,11,12]$, and $30 \%$ of the dogs may exhibit recurrence signs owing to the formation of the dorsal lamina [7]. We believe that, in the case described here, chronicity of the disease, severe disuse muscle atrophy, and age of the patient did not allow a full neurological recovery. Additionally, spinal cord atrophy is reportedly possible in chronic cases of CSM and is associated with an unfavorable prognosis [16].

The results presented in this report indicate that cervical laminectomy procedures are clinically relevant for the treatment of ventral disc compression, especially in chronic cases in which dorsal (bone) compressions are present, as demonstrated by attenuation of the compression seen on the postoperative myelogram. Since there are no studies showing a direct comparison between surgical techniques for the treatment of CSM, case reports become important for discussion of this topic.

\section{MANUFACTURERS}

${ }^{1}$ Teuto Pfizer. Anapólis, GO, Brazil.

${ }^{2}$ Medley Farmacêutica Ltda. Campinas, SP, Brazil.

${ }^{3}$ Merial. Campinas, SP, Brazil.

${ }^{4}$ Neo Química Comércio e Industria Ltda. São Paulo, SP, Brazil.

${ }^{5}$ Sanofi Aventis. Suzano, SP, Brazil.

Declaration of interest. The authors report no conflicts of interest. The authors alone are responsible for the contents and writing of the paper.

\section{REFERENCES}

1 Araujo B.M., Figueiredo M.L., Silva A.C., Fernandes T.H.T., Bonelli M.A. \& Tudury E.A. 2013. Lesão iatrogênica meningomedular em um cão submetido à espondilectomia ventral para tratamento de extrusão crônica de disco intervertebral cervical. Arquivo Brasileiro de Medicina Veterinária e Zootecnia. 65(3): 649-653.

2 Da Costa R.C., Parent J.P. \& Dobson H. 2006. Comparison of magnetic resonance imaging and myelography in 18 Doberman pinscher dogs with cervical spondylomyelopathy. Veterinary Radiology and Ultrasound. 47(6): 523-531.

3 Da Costa R.C. 2007. Pathogenesis of cervical spondylomyelopathy: lessons from recent years. In: Proceedings Proceedings of the 25th Annual American College of Veterinary Internal Medicine, ACVIM Forum (Seattle, U.S.A.). pp.318-320.

4 Da Costa R.C. 2010. Cervical spondylomyelopathy (wobbler syndrome) in dogs. The Veterinary Clinics of North America. Small Animal Practice. 40(5): 881-913.

5 De Decker S., Bhatt S., Gielen I. \& Van Ham L. 2008. Diagnosis, treatment and prognosis of disc associated Wobbler syndrome in dogs. American Journal of Veterinary Research. 77(3): 139-147.

6 De Lahunta A. \& Glass E.N. 2009. General sensory systems: general proprioception and general somatic afferent. In: de Lahunta A. \& Glass E.N. (Eds). Veterinary Neuroanatomy and Clinical Neurology. St. Louis: Saunders, pp.221-242.

7 De risio L., Munana K., Murray M., Olby N., Sharp N.J. \& Cuddon P. 2002. Dorsal laminectomy for caudal cervical spondylomyelopathy: postoperative recovery and long-term follow-up in 20 dogs. Veterinary Surgery. 31(5): 418-427.

8 Dewey C.W. 2013. Surgery of the cervical spine. In: Fossum T.W. (Ed). Small Animal Surgery. St. Louis: Elsevier Mosby, pp.1467-1507.

9 Jeffery N.D. \& Mckee W.M. 2001. Surgery for disc-associated wobbler syndrome in the dog - an examination of the controversy. Journal of Small Animal Practice. 42(12): 574-581.

10 Lecouteur R.A. \& Grandy J.L. 2004. Doenças da medula espinhal. In: Ettinger S.J. \& Feldman E.C. (Eds). Tratado de medicina interna veterinária: Moléstias do cão e do gato. Rio de Janeiro: Guanabara Koogan, pp.664-94.

11 Lipsitz D., Levitski R.E., Chauvet A.E. \& Berry W.L. 2001. Magnetic resonance imaging features of cervical stenotic 
G. Sembenelli, M.C.N. Wittmaack, L. Oliveira, P.C. Moraes, B.W. Minto \& L.G.G.G. Dias. 2016. Cervical Laminectomy for the Treatment of Chronic Caudal Cervical Spondylomyelopathy in a Dog. Acta Scientiae Veterinariae. 44(Suppl 1): 156.

myelopathy in 21 dogs. Veterinary Radiology \& Ultrasound. 42(1): 20-27.

12 Lyman R. 1990. Continuous dorsal laminectomy for the treatment of caudal cervical instability and malformation. In: Proceedings of the 13th Kal Kan Symposium. (Vernon, USA). pp.13-16.

13 Mckee W.M. \& Sharp N.J. 2003. Cervical spondylopathy. In: Slatter D. (Ed). Textbook of Small Animal Surgery. Philadelphia: Saunders, pp.1180-1193.

14Platt S.R. \& Da Costa R.C. 2012. Cervical Spine. In: Tobias K.M. \& Johnston S.A. (Eds). Veterinary Surgery - Small Animal. St. Louis: Elsevier, pp.410-448.

15 Seim H.B. \& Withrow S.J. 1982. Pathophysiology and diagnosis of caudal cervical spondylo-myelopathy with emphasis on the Doberman Pinscher. Journal of the American Animal Hospital Association. 18: 241-251.

16Sharp N.J.H., Cofone M., Robertson I.D., DeCarlo A., Smith G.K. \& Thrall D.E. 1995. Computed tomography in the evaluation of caudal cervical spondylomyelopathy of the Doberman Pinscher. Veterinary Radiology \& Ultrasound. 36(2): 100-108.

17 Sharp N.J.H. \& Wheeler S.J. 2005. Cervical spondylomyelopathy. In: Sharp N.J.H. \& Wheeler S.J. (Eds). Small animal spinal disorders-diagnosis and surgery. Philadelphia: Elsevier Mosby, pp.211-246.

18Sharp N.J.H., Wheeler S.J. \& Cofone M. 1992. Radiological evaluation of "wobbler" syndrome-caudal cervical spondylomyelopathy. Journal of Small Animal Practice. 33(10): 491-499.

19 Toombs J.P. \& Waters D.J. 2003. Intervertebral Disc Disease. In: Slatter D. (Ed). Text book of small animal surgery. 3rd edn. Philadelphia: Saunders, pp.1193-1208.

20 Vangundy T.E. 1988. Disc-associated wobbler syndrome in the Doberman Pinscher. Veterinary Clinics of North America: Small Animal Practice. 18(3): 667-696. 